\title{
Implicit Microfoundations for Macroeconomics
}

\author{
Ian Wright \\ The Open University, Milton Keynes
}

\begin{abstract}
A large market economy has a huge number of degrees of freedom with weak microlevel coordination. The 'implicit microfoundations' approach considers this property of micro-level interactions to more strongly determine macro-level outcomes compared to the precise details of individual choice behavior; that is, the 'particle' nature of individuals dominates their 'mechanical' nature. So rather than taking an 'explicit microfoundations' approach, in which individuals are represented as 'white-box' sources of fully-specified optimizing behavior ('rational agents'), we instead represent individuals as 'black box' sources of unpredictable noise subject to objective constraints ('zero-intelligence agents'). To illustrate the potential of the approach we examine a parsimonious, agent-based macroeconomic model with implicit microfoundations. It generates many of the reported empirical distributions of capitalist economies, including the distribution of income, firm sizes, firm growth, GDP and recessions.
\end{abstract}

Special issue Reconstructing Macroeconomics

JEL: A12, B41, C63, D50, E11, P16

Keywords: Microfoundations; macroeconomics; aggregation, power laws

\section{Correspondence}

Ian Wright, Department of Economics, Faculty of Social Sciences, The Open University, Walton Hall, Milton Keynes, MK76AA, UK; e-mail: wrighti@acm.org

This work is the result of the author's current PhD studies supervised by Andrew Trigg at the Open University. The author thanks the editors of this special issue and the anonymous referees for helpful feedback. 


\section{Statistical Equilibrium and Implicit Microfoun- dations}

Macroeconomic phenomena are partly determined by the aggregated outcome of the microeconomic decisions of the individuals that comprise the economy. It therefore makes sense to seek macroeconomic theories that have microfoundations as essential elements. But what kind of microfoundations?

A traditional approach to this question explains macroeconomic phenomena in terms of microfoundations that consist of (i) a precise theory of individual choice and (ii) a complete specification of the relevant information that defines the contexts in which choices are made (e.g., see Kydland and Prescott (1982) for a canonical example). So the microfoundations normally take the form of inter-temporal optimization of an objective function (a mechanism of choice) given individual endowments, preferences and technology (a range of situations). Macroeconomic fluctuations in output, employment, investment and consumption are then explained in terms of exogenous technology shocks. The microfoundations are explicit because the choice mechanism (optimization) is fully specified and functions as an essential explanatory factor.

The explicit microfoundations approach encounters some logical difficulties when the decisions of many individuals are aggregated (e.g., see Rivzi (1994) and Gaffeo et al. (2007)). So the device of a 'representative agent' is normally employed to map a very large inhomogeneous population to a very small set of homogeneous individuals. The idea is that the law of large numbers applies to a large population so that individual variances shrink to zero upon aggregation. So the means of variables, associated with the representative agent, can function as 'sufficient statistics' for the population as a whole. But in many situations individual variances do not 'wash out' in the aggregate so the representative agent will misrepresent the aggregate consequences of the microfoundations (e.g., see Aoki and Yoshikawa (2007) and Farjoun and Machover (1989), Ch. 1). Quoting Kirman (1992), 'there is no plausible formal justification for the assumption that the aggregate of individuals, even maximizers, acts itself like an individual maximizer'.

But here I would like to focus on a more fundamental concern: Is the precise mechanism of individual choice an important causal factor in the determination of macroeconomic phenomena? The explicit microfoundations approach answers 'yes'. Alternatively, if the answer is 'no' then the traditional approach, at the very least, contributes a redundant explanatory factor to the construction of macroeconomic theories.

Farjoun and Machover (1989), in their path-breaking work on Political Economy, 'Laws of Chaos', make a simple but important methodological point. They observe that an economy is a dynamic system composed of millions of people in which 'the actions of any two firms or consumers are in general almost independent of each other, although each depends to a very considerable extent on the sum total of the actions of all the rest' (Farjoun and Machover (1989), p.39); in other words, a market economy has a huge number of degrees of freedom (DOF) with weak microlevel coordination. They argue that the appropriate equilibrium concept for such a system is a statistical equilibrium in which the macro-level regularities take the form 
of probability distributions. Let's explore their thesis for a moment.

The economy of the United States has a civilian labor force of approximately 155 million individuals. 1 The kinds of economic activities performed by these individuals spans the whole range of human experience and subsumes a great variety of tasks, skills, situations, enjoyments and motives. An enormous variety of both mundane and novel decision-making contexts are routinely presented to the individuals that constitute the economy. The space of possible configurations of this system is of course astronomically large.

Local economic decisions are globally coordinated primarily through the 'invisible hand' of supply and demand dynamics in markets distributed in time and space. The economy gropes this way and that, from one configuration to another, generally in a 'bottom-up' manner, adapting continually to new economic circumstances. The existence of this type of emergent coordination does not significantly reduce the DOF since there is no top-down plan or 'Walrasian auctioneer' to synchronize the local behavior.

Systems that have a huge number of DOF and weak micro-level coordination ('messy' systems) behave very differently to systems with a small number of DOF and strong micro-level coordination ('neat' systems). This is reflected in the different kinds of equilibrium they can exhibit.

The state-space of a system is the set of all possible configurations of the DOF. A particular configuration is a 'point' in state space. In general we find that many neat systems, if they enter equilibrium, tend toward a point or trajectory in state-space. A canonical example is a set of weighing scales. Place some weights on each arm and the scales will tend toward an equilibrium point in which the internal forces balance and the system is at rest. This is a simple kind of deterministic equilibrium, in which the equilibrium configuration is a subset of state-space. The classical mechanics concept of equilibrium was a founding metaphor of the 19th Century marginal revolution in economics (e.g., see Mirowski (1989)). And it appears in a more developed form in 20th Century neoclassical general equilibrium models (e.g., Debreu (1959)).

But most messy systems, if they enter equilibrium, do not tend toward a subset of state-space. So in the physical sciences the tools of statistical, not classical, mechanics are used to study messy systems. A canonical example is an ideal gas in a container. The internal forces never balance. Instead, at the micro-level, there is ceaseless motion and change, a process that effectively samples the whole state-space in a random fashion. Yet at the macro-level a certain kind of regularity does emerge. The probability that a randomly selected gas particle will have a certain energy is constant over time (in this case, the probability distribution is Boltzmann-Gibbs). In this simple kind of statistical equilibrium the equilibrium configuration is not a 'point' or subset of state-space but a probability distribution over an aggregate transform of the state-space (in this case, the number of atoms with a given energy level).

Since an economy is more like a messy than a neat system we should expect any empirical regularities to be better captured by the concept of a statistical, rather than a deterministic, equilibrium. Essentially this is Farjoun and Machover's point.

\footnotetext{
${ }^{1}$ According to the US Bureau of Labor Statistics (2008).
} 
The importance of statistical equilibrium in economics has been emphasized by other authors, notably Steindl (1965), and more recently Aoki (1996, 2002) and Foley (1994).2 Nonetheless, thinking that the relation between micro and macro in statistical mechanics is related to the analogous problem in economics remains the 'less trodden path'. One reason, perhaps, is that it calls into question the need for explicit microfoundations.

A counter-intuitive property of statistical mechanics is that macro-level regularities are in an important sense relatively independent of the precise mechanisms that govern the micro-level interactions. So the adoption of macro-level statistical equilibrium as an explanatory principle has a concomitant implication for microfoundations. For example, classical statistical mechanics represents the molecules of a gas as idealized, perfectly elastic billiard balls, which is a gross oversimplification of a molecule's structure and how it interacts with other molecules. Yet statistical mechanics can deduce empirically valid macro-phenomena. Khinchin (1949), who pioneered the development of mathematical foundations for the field, writes:

Those general laws of mechanics which are used in statistical mechanics are necessary for any motions of material particles, no matter what are the forces causing such motions. It is a complete abstraction from the nature of these forces, that gives to statistical mechanics its specific features and contributes to its deductions all the necessary flexibility. ... the specific character of the systems studied in statistical mechanics consists mainly in the enormous number of degrees of freedom which these systems possess. Methodologically this means that the standpoint of statistical mechanics is determined not by the mechanical nature, but by the particle structure of matter. It almost seems as if the purpose of statistical mechanics is to observe how far reaching are the deductions made on the basis of the atomic structure of matter, irrespective of the nature of these atoms and the laws of their interaction. (Eng. trans. Dover, 1949, pp. 8-9, emphasis added).

So, analogously, the method by which individuals choose (the 'mechanical' nature of individuals) is not as important as the fact that a huge number of individuals are choosing with respect to each other but are weakly coordinated (the "particle' nature of individuals). The approach of implicit microfoundations adopts this methodological 'rule of thumb'.

Given the aim is to determine 'how far reaching are the deductions made on the basis' of the particle nature of individuals while abstracting from the mechanics of individual rationality, it makes sense, at least initially, to 'bend the stick' as far as possible in the direction of implicit microfoundations. But how do we abstract from the 'mechanics' of individual rationality and represent individuals as 'particles'?

Sometimes it is possible to predict choice behavior in controlled experimental settings or in situations where conventions or rules play an important role. But

\footnotetext{
${ }^{2}$ In the Econophysics literature the work of Dragulescu and Yakovenko (2000), although relying on a highly simplified definition of money and monetary exchange, is nonetheless an instructive and beautiful example of the power of statistical mechanical approaches to understanding macroeconomic distributions.
} 
in general the everyday creativity of market participants who aim to satisfy their goals in open-ended and mutually constructed economic situations is unpredictable. For example, Aoki (2002) writes, 'Even if agents inter-temporally maximize their respective objective functions, their environments or constraints all differ and are always subject to idiosyncratic shocks. Our alternative approach emphasizes that an outcome of interactions of a large number of agents facing such incessant idiosyncratic shocks cannot be described by a response of the representative agent and calls for a model of stochastic processes'. The unpredictability of choice behavior suggests representing the choice mechanism as a random process. So the implicit approach represents economic agents not as 'white box' sources of predictable optimizing behavior but instead as 'black box' sources of unpredictable noise; that is, they are particles that choose in a random manner subject to objective constraints (e.g., a budget constraint). The single representative agent with well-defined choice behavior has been replaced by a huge number of heterogeneous agents with random choice behavior. This is the simplest possible starting point for implicit microfoundations and provides a null hypothesis against which claims of the importance of explicit microfoundations can be measured. For example, as a starting point, randomness can be modeled as selection from a uniform distribution, in accordance with Bernoulli's Principle of Insufficient Reason that states that in the absence of knowledge to the contrary assume all outcomes are equally likely. The aim is 'to explain more by saying less', or at least start by saying less and see how far that takes us (c.f. Farmer et al. (2005)).

The principle that many market outcomes are determined more by the objective social structure than the particulars of individual rationality is not new. For example, Gode and Sunder (1993) show that the results of an economics experiment are broadly similar when classroom students are replaced with 'zero-intelligence', random agents; Farmer et al. (2005) show that the assumption of 'zero-intelligence' agents can explain many of the statistical features of double-auction trading data from the London Stock Exchange; and Wright (2008) shows that 'zero-intelligence' agents in a simple commodity economy can instantiate supply and demand dynamics that approach efficient allocation of resources and equilibrium prices (see also Cottrell et al. (2009)).

A natural objection at this point is the observation that economic agents do not act according to random rules. They often think very carefully before acting. Surely it is necessary, therefore, to model individual rationality, even when considering macro-level phenomena? But the objection elides the distinction between epistemology and ontology, a picture with reality. A 'black box' probabilistic model of individual agency does not imply that choice mechanisms are in fact random, only that, when placed in the range of situations routinely presented by a dynamic, large-scale economy, they are operationally equivalent, at the aggregate level, to an ensemble of random process. So the precise detail of the choice mechanism is not a decisive factor in the determination of macro-level outcomes.

Randomness in a theory can be viewed as an unmodeled residual, like assuming a constant in physical theories (e.g. the constant of gravitation). Residuals should eventually be eliminated and replaced by a more encompassing theory (e.g. a theory that explains the value of the gravitational constant). But the 'rule of thumb' of 
implicit microfoundations says something different: eliminating randomness won't necessarily yield a better explanatory or predictive theory since the randomness represents an essential property of 'messy' systems. We should expect rapidly diminishing explanatory returns from increasingly explicit microfoundations.

Any methodological suggestions need testing. The next section provides an example of a parsimonious, agent-based macroeconomic model with implicit microfoundations. The computational model facilitates a quick, experimental exploration of the consequences of adopting implicit microfoundations. On execution it rapidly self-organizes into a statistical equilibrium with properties that replicate many of the reported empirical distributions of developed capitalist economies.

\section{An Example of Implicit Microfoundations}

The 'social relations of production' (Marx, 1954) define roles that people fulfill when engaged in productive activity. A defining feature of a capitalist economy is the employee-employer relation. A small class of capitalists employ a large class of workers organized in firms. The capitalist owners are the residual claimants of firm income and receive profits, whereas workers are hired, or rented, and receive wages. In reality some individuals receive both profit and wage income (and other kinds of income). Nonetheless the vast majority of the working population rely on wage income. This close correlation between the personal and the functional distribution of income is the foundation of the the two major economic classes of capitalist society. Hence we adopt the simplifying assumption that an agent is either an employee or an employer.

The social relations of production both enable and constrain the kinds of economic interactions between individuals. These social constraints are distinct from any natural or technical constraints, such as those due to scarcities or current production techniques. So this model entirely abstracts from natural and technical constraints and instead concentrates on the relationship between economic actors mediated by monetary exchange. The model ontology is therefore quite sparse, consisting solely of individuals and money. The aim is to concentrate as far as possible on the economic consequences of the social relations of production alone rather than particular and perhaps transitory economic mechanisms, such as particular markets, commodity types and industries. ${ }^{3}$

Consider $N$ economic agents labelled $1, \ldots, N$. Each agent $i$ owns a non-negative amount of money, $m_{i}$. The total money in the economy is a finite constant $M=$ $\sum_{i=1}^{N} m_{i}$.

Each agent has an integer employer index, $0 \leq e_{i} \leq N$ and $e_{i} \neq i$, which denotes the agent's employer. If $e_{i}=0$ the agent is not employed; otherwise if $e_{i}=j$ then agent $j$ is the employer of agent $i$.

Each agent has a wage level, $w_{i} \geq 0$, which represents the last wage payment received from an employer. Each agent has a wage expectation, $\eta_{i} \geq 0$, which represents the wage payment it expects to receive from an employer.

\footnotetext{
${ }^{3}$ This model extends previous work described in reference (Wright, 2005b), in particular by simpifying the computational rules and introducing a labor market and endogenous wage rate.
} 
The state of each agent is fully specified by the tuple $\left(m_{i}, e_{i}, w_{i}, \eta_{i}\right)$.

At any time the economy supports an 'effective demand', $0 \leq D \leq M$, which represents the total monies available for the purchase of goods and services.

The static state of the whole economy is fully specified by the set of tuples $S=\left\{\left(m_{i}, e_{i}, w_{i}, \eta_{i}\right): 1 \leq i \leq N\right\}$ and effective demand $D$.

The evolution of the state of the economy, $S_{i} \rightarrow S_{i+1}$, is determined by a set of five simple rules, which are repeatedly applied at each simulation step.

\subsection{The Labor Market}

The labor market assigns workers to firms at different wage levels. Assume that: unemployed agents seek employment; their wage expectations tend to decrease during the period of unemployment; employed agents tend to join new employers if the pay is better or remain if they receive a pay rise; cash-rich employers tend to demand more labor resources than poorer employers; and demand for labor tends to increase wage expectations. These informal assumptions are expressed more precisely by the following rule.

Hiring rule: If agent $a$ is not an employer, $\forall x: e_{x} \neq a$, then:

1. Wealthier employers have a higher probability of matching with potential hires in the job market. Form the set of potential employers, $H=\left\{x: e_{x}=\right.$ $0 \wedge x \neq a, 1 \leq x \leq N\}$. Select a potential employer, $h \in H$, with probability $P(h)=m_{h} / \sum_{i \in H} m_{i}$, which weighs potential employers by their wealth.

2. Demand for labor tends to increase wage expectations. Select the negotiated wage offer, $w$, from the interval $\left[\eta_{a}, 2 \eta_{a}\right]$ according to a uniform distribution (unless $w$ exceeds the potential employer's wealth, $w_{h}$, in which case set $w=$ $w_{h}$ ). If $w>\eta_{a}$ (i.e., the wage offer exceeds the wage expectation) then firm $h$ hires $a$. Set

(a) the employer index $e_{a}$ to $h$ and

(b) the new wage expectation $\eta_{a}$ to the accepted offer $w$.

3. Lack of demand for labor tends to decrease wage expectations. Otherwise if a remains unemployed, $e_{a}=0$, then randomly select a new wage expectation, $\eta_{a}^{\prime}$, from the interval $\left[0, \eta_{a}\right]$ according to a uniform distribution (i.e., $\eta_{a}$ is set to $\left.\eta_{a}^{\prime}\right)$.

Wage expectations are initially subjective and arbitrary but they change in response to the conditions in the labor market. Unemployment tends to lower the wage expectation by $50 \%$ whereas getting hired or rehired tends to raise the wage expectation by $50 \%$. The expectation delta is a minor parameter that controls the rate of change of wage expectations.

The hiring rule allows all those not employed to potentially hire employees. A small firm is born when an unemployed agent with sufficient cash hires another unemployed agent.

A major simplifying assumption is that every firm has a single capitalist owner who does not reallocate their capital during the lifetime of the firm. 


\subsection{Effective Demand}

Assume that: the total amount spent by an individual agent is bounded by their current cash holdings; the expenditure contributes to the total effective demand in the economy; and workers purchase consumption goods and capitalists also purchase capital goods. So effective demand can be interpreted to consist of both personal consumption and investment.

Effective demand rule $: 4$ All agents spend a proportion of their income on goods and services.

1. Randomly select an expenditure amount, $m$, from the interval $\left[0, m_{a}\right]$ according to a uniform distribution.

2. Transfer $m$ to effective demand $D$ (hence, $m_{a}$ is reduced by $m$ and $D$ is increased by $m$ ).

In other words, agents spend randomly given their budget constraint.

\subsection{Interaction Between Firms and the Effective demand}

Assume that every member of a firm, both employees and employer, performs work that potentially adds value to firm output. Clearly there are multiple and particular reasons why a worker adds more or less value, including the capital of the firm. But the value that is added must be bound by the effective demand.

Firm revenue rule: All members of a firm perform activities that generate income. If agent $a$ is not unemployed, $e_{a} \neq 0 \vee \exists x: e_{x}=a$, then:

1. Randomly select an amount of revenue $m$ from the interval $[0, D]$ according to a uniform distribution ( $D$ is reduced by $m$ ).

2. If agent $a$ is an employee, $e_{a} \neq 0$, then transfer $m$ to the employer $e_{a}$ (hence $m_{e_{a}}$ is increased by $m$ ).

3. If agent $a$ is an employer, $\exists x: e_{x}=a$, then transfer $m$ to $a$ (hence $m_{a}$ is increased by $m$ ).

A firm with more employees will on average receive a share of the effective demand on more occasions than a firm with fewer employees. The income represents the value of many different kinds of products and services sold in arbitrary amounts to arbitrary numbers of buyers.

\subsection{Wage Payments and Employee Firing}

The employer pays wages from its cash reserves. If a wage cannot be paid then the employee is fired. Firing may therefore occur in bulk if the firm is cash starved. A firm ceases trading when all its employees are fired.

Wage payment and firing rule: Employers pay wages. An employee is fired if the employer cannot afford to pay their wage. If agent $a$ is an employer, $\exists x: e_{x}=a$, then form the set of employees $E=\left\{x: e_{x}=a, 1 \leq x \leq N\right\}$. For each $b \in E$ :

${ }^{4}$ Following Lin (2008) I simplify this rule compared to Wright (2005b). 
1. If employer $a$ has sufficient funds (i.e., $m_{a} \geq \eta_{b}$ ) then transfer wage payment $\eta_{b}$ to employee $b$. Set the employee's wage level to the wage payment, $w_{b}=\eta_{b}$.

2. If employer $a$ has insufficient funds (i.e., $m_{a}<\eta_{b}$ ) then employee $b$ is fired $\left(e_{b}\right.$ is set to 0$)$. Set the fired employee's wage expectation to the wage level, $\eta_{b}=w_{b}$.

An employee is hired at a specific pay level on entry to the firm (the 'wage contract') represented by the wage expectation. But if the agent is fired before they get paid then the wage expectation reverts to the agent's previous wage level. The expectation was never met. If all employees are fired then the firm has ceased trading.

\subsection{Historical Time}

Each 'month' every agent has a chance to act.

One month rule: Select $N$ agents with replacement from the set $S$ to form the set of active agents $A$. For each $a \in A$ apply the:

1. Hiring rule.

2. Effective demand rule.

3. Firm income rule.

4. Wage payment and firing rule.

Since $N$ agents are selected with replacement then some agents may act more than once and others not at all, which introduces an additional source of noise. 5

The one month rule generates a variety of events. Agents can get hired, fired, switch jobs, or get pay raises. They may form start-ups. Firms grow and shrink in size. Workers generate revenue for the firms that employ them. The revenue is bound by the effective demand, which is a function of the stochastic spending patterns of other agents. Firms pay out wages, or cease trading if they cannot afford to do so. And so forth.

The five rules constitute a 'closed social architecture model' (CSA). It has two major parameters, the population size, $N$, and the total money stock, $M$. The Mathematica 6.0 code that implements the model is included in the appendix.

\section{Graphical Analysis}

Parameters $M$ and $N$ appear to function as scaling parameters that do not affect the relative dynamics, except when finite size effects occur at approximately $N<50$. The state of each agent must be seeded. At initialization all agents are unemployed with a money endowment of 10. All wage expectations and levels are also set to 10. This is an arbitrary choice. Later, in section 3.12, we show that the seeds do not affect the results. In all reported results, $N=1000$ and $M=10000$.

\footnotetext{
${ }^{5}$ Lin (2008) justifiably complains that this choice is unrealistic and lacks a strong economic justification. I agree that it is important to remove this feature from the model. I stick with it for now since I find it produces a superior firm size distribution.
} 


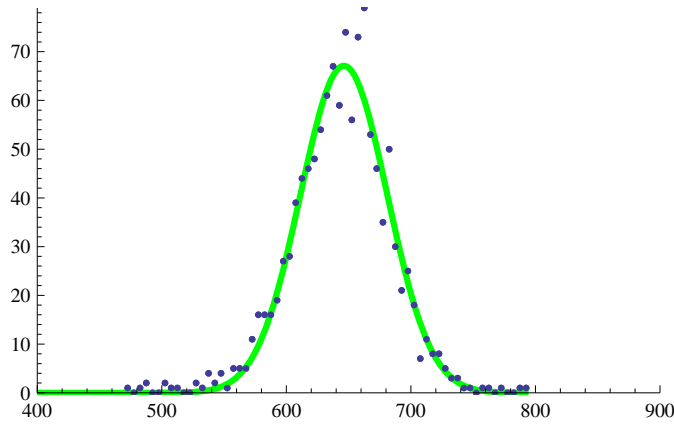

(a) Frequency plot of number of workers, $\mu=646.2$ (64.6\% of the population) and $\sigma=34.9$.

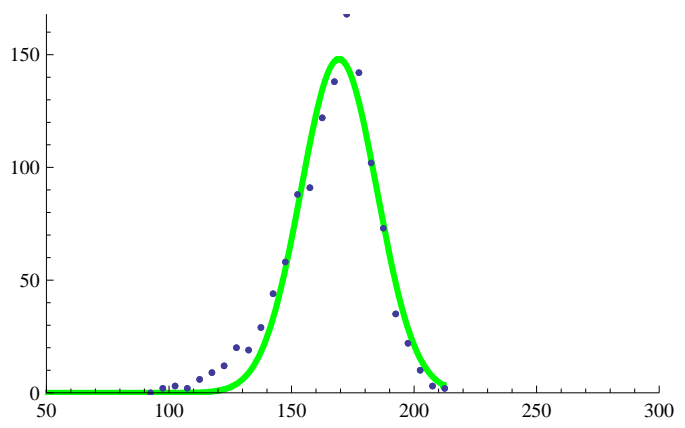

(b) Frequency plot of number of capitalists, $\mu=169.3$ (16.9\% of the population) and $\sigma=$ 15.5 .

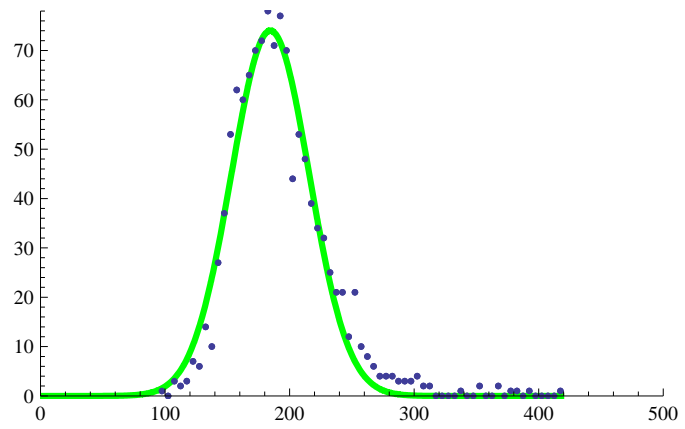

(c) Frequency plot of number of unemployed, $\mu=184.5$ (18.5\% of the population) and $\sigma=31.3$.

Figure 1: Frequency plots of class sizes (bin size of 5 ). The smooth curves are normal distributions $P(x) \propto \frac{1}{\sigma \sqrt{2 \pi}} e^{-(x-\mu)^{2} /\left(2 \sigma^{2}\right)}$.

The simulation rapidly converges to a state of statistical equilibrium. Once this state is reached we collect statistics for 100 years. Since the results are not sensitive to initial conditions we examine the results from a single execution. All functional fits are based on a simple least-mean-squared error. So the analysis should be considered only preliminary and indicative.

\subsection{Economic Classes}

In capitalist economies the capitalist class is numerically small whereas the working class, that is those who rely predominately on wage income, constitute the vast majority of the population. After each year we count the number of workers, capitalists and unemployed. Figure 1 plots the result. Class sizes are approximately normally distributed. The normal distributions summarize a dynamic process that supports social mobility, where agents move between classes during their imputed lifetimes, occurring within a stable partition of the population into two main classes - a small employing class and a larger employed class. The CSA model therefore self-organizes into a realistic partition of the working population into a minority of employers and a majority of employees.

The unemployment rate is higher than is usually reported in modern economies, but real measures of unemployment typically under-report actual unemployment, 


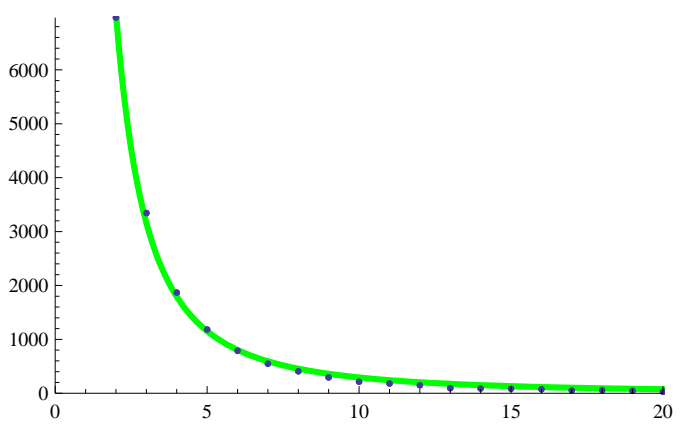

(a) The smooth curve is a Pareto distribution $P(x) \propto x^{-(\alpha+1)}$ with exponent $\alpha=$ 0.98. The special case $\alpha=1$ is the Zipf distribution.

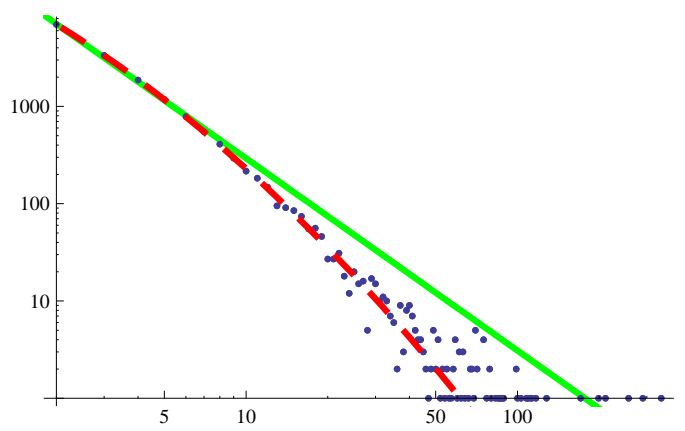

(b) Frequency plot in log-log scale. The straight line is the same Pareto distribution. The dashed line is a lognormal distribution $P(x) \propto(1 / \sigma) e^{-\left((\ln x-\mu)^{2} / 2 \sigma^{2}\right)}$. with $\mu=-0.7$ and $\sigma=1.4$.

Figure 2: Frequency plots of firm sizes measured by number of employees (bin size of 1$)$.

whereas here all non-employed actors are considered unemployed; in addition there is no concept of self-employment in the model.

\subsection{Firm Sizes}

After each month we count the number of employees in each firm. Figure 2 plots the result, which is consistent with either the Zipf (power-law) distribution or the lognormal distribution. There are many small firms and a small number of very large firms. A similar results is obtained if firm sizes are measured over a much shorted period, such as 15 years.

Gibrat (1931) proposed that firm sizes follow a lognormal distribution. Early empirical studies supported this hypothesis (e.g., Hart and Prais (1956), Simon and Bonini (1958)). Axtell (2001) analyzed US Census Bureau data for US firms trading between 1988 and 1997 and found that the firm size distribution is Zipf, and this relationship persisted from year to year despite the continual birth and demise of firms and other major economic changes. Gaffeo et al. (2003) found that the size distribution of firms in the G7 group over the period 1987-2000 also followed a power-law, but only in limited cases was the power-law actually Zipf. Fujiwara (2004) found that the Zipf law characterized the size distribution of about 260,000 large firms from 45 European countries during the years 1992-2001.

Lognormal distributions can generate tails that appear to follow a power-law. So a statistical, rather than graphical analysis, is needed to distinguish between powerlaw and lognormal fits. The CSA model is therefore consistent with the empirical distribution of firm sizes relative to this uncertainty.

The largest US firm in 1997 had approximately $10^{6}$ employees from a total reported workforce of about $10^{7}$ individuals (Axtell, 2001). Therefore, the largest firm size should not exceed about $\frac{1}{10}$ th of the total workforce. Figure 2 shows that, with low but non-zero probability, a single firm can employ nearly $40 \%$ of the workforce, representing a monopolization of a significant proportion of the economy by a single 


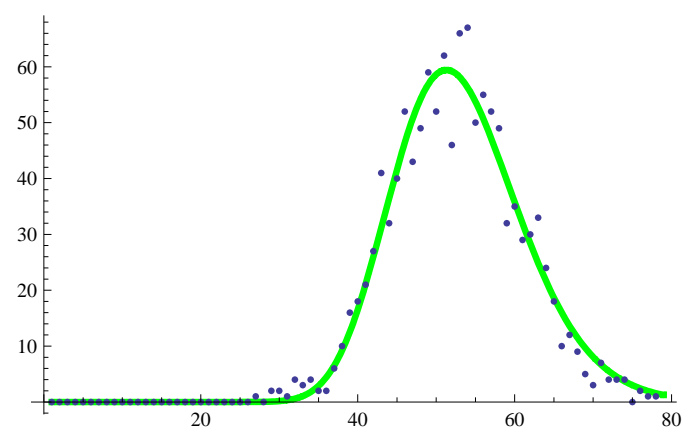

Figure 3: Frequency plot of number of firm demises per month (bin size of 1). The smooth curve is the lognormal distribution $P(x) \propto(1 / \sigma) e^{-\left((\ln x-\mu)^{2} / 2 \sigma^{2}\right)}$. with $\mu=3.9$ and $\sigma=-6.4$.

firm, a clearly unrealistic occurrence. A possible reason for the over-monopolization of the economy is the assumption that firms have a single capitalist owner, which conflates capital concentration with firm ownership. In a more realistic model capitalists would invest in a portfolio of firms and reallocate their capital according to the rate of return. So profit would have a weaker tendency to get 'locked-in' to a single firm and generate positive-feedback growth.

\subsection{Firm Demises}

When a firm fires all its employees it 'dies'. We measure the number of firm demises per month. Figure 3 plots the result. The results are consistent with a lognormal distribution. Cook and Ormerod (2003) report that the distribution of US firm demises per year during the period 1989 to 1997 is closely approximated by a lognormal distribution. The CSA model is therefore consistent with the empirical distribution of firm sizes.

The average number of firms in the US during the period 1989 to 1997 was 5.73 million, of which on average 611,000 died each year (Cook and Ormerod, 2003). So roughly $10 \%$ of firms die each year. In the simulation on average 52 firms die each month and therefore approximately 630 firms die each year, a figure in excess of the 170 firms that exist on average. So although the distribution of firm demises is consistent with empirical data, the rate at which firms die is much higher than in reality.

\subsection{Firm Lifespans}

When a firm dies we measure the number of months it traded. Figure 4 plots the result, which is consistent with an exponential distribution in which the majority of firms have a short lifespan and a minority a long lifespan. Gatti et al. (2004) analyzed the age at bankruptcy of about 6 million European firms from 1992 to 2001 and found that the distribution is exponential. Fujiwara (2003) analyzed data on about 16,000 Japanese firms in 1997 and found similar results. The CSA model is therefore consistent with the empirical distribution of firm lifespans. 


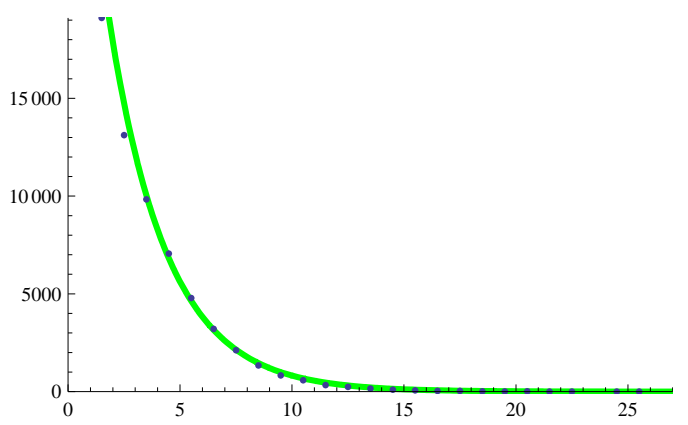

(a) The smooth curve is the exponential distribution $P(x) \propto \lambda e^{-\lambda x}$ with $\lambda=0.39$.

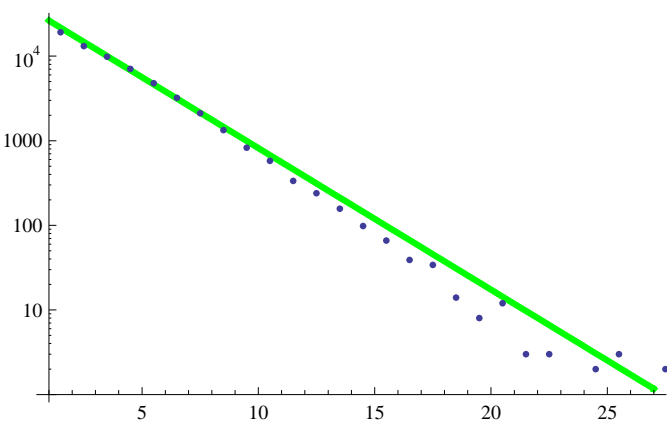

(b) Frequency plot in log scale. The straight line is the same exponential distribution

Figure 4: Frequency plot of firm lifespans measured in months (bin size of 2).

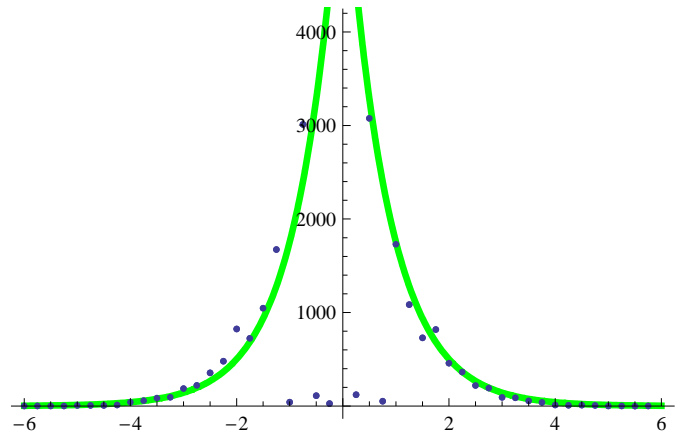

(a) The smooth curve is the Laplace distribution $P(x) \propto e^{-\lambda|x|}$ with $\lambda=1.3$.

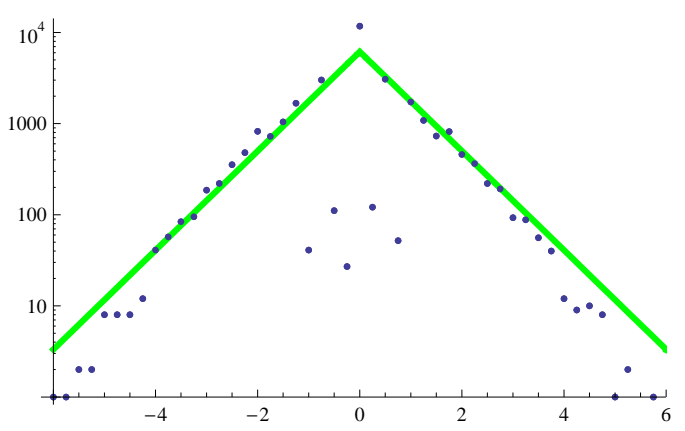

(b) Frequency plot in log scale. The straight line is the same Laplace distribution.

Figure 5: Frequency plots of $\log$ of firm growth $\ln \left(s_{t} / s_{t-1}\right)$ measured by number of employees (bin size of 0.25 ).

\subsection{Firm Growth}

After each year we measure the current size, $s_{t}$, of each firm that is trading at the end of the year. Size is defined by the number of employees. The log growth rate is then $\ln \left(s_{t} / s_{t-1}\right)$ (if a firm ceased trading in year $t$ or $t-1$ then no growth rate is recorded). Figure 5 plots the result, which is consistent with a Laplace (double exponential) distribution.

Stanley et al. (1996) and Amaral et al. (1997) analyzed the log growth rates of publicly traded US manufacturing firms in the period 1974 - 93 and found that growth rates, when aggregated across all sectors, appear to robustly follow a Laplace form with some deviation from the Laplace at high and low growth rates resulting in slightly 'fatter wings' (Lee et al., 1998, Amaral et al., 2001). Bottazzi and Secchi (2003) replicate these findings and report a Laplace growth distribution for Italian manufacturing firms during the period 1989-96. This holds true whether growth rates are measured by sales or number of employees.

Figure 6 plots the result when size is defined by sales revenue. The result is consistent with a Subbotin, not an exponential, distribution. The Gaussian and Laplace distributions are special cases of the Subbotin distribution. Teitelbaum and Axtell (2005) re-examined Stanley et al.'s data and concluded that in several cases a Sub- 


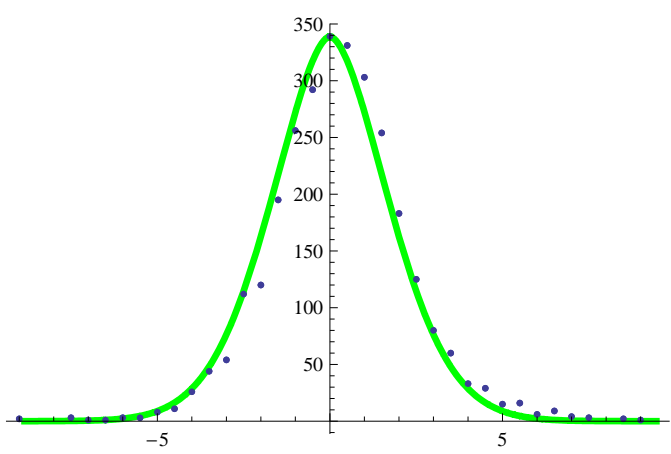

(a) The smooth curve is the Subbotin distribution $P(x) \propto \frac{1}{2 a b^{1 / b} \Gamma(1 / b+1)} e^{-(1 / b)|x / a|^{b}}$ where $\Gamma(x)$ is the Gamma function, $a=1.7$ and $b=1.7$.

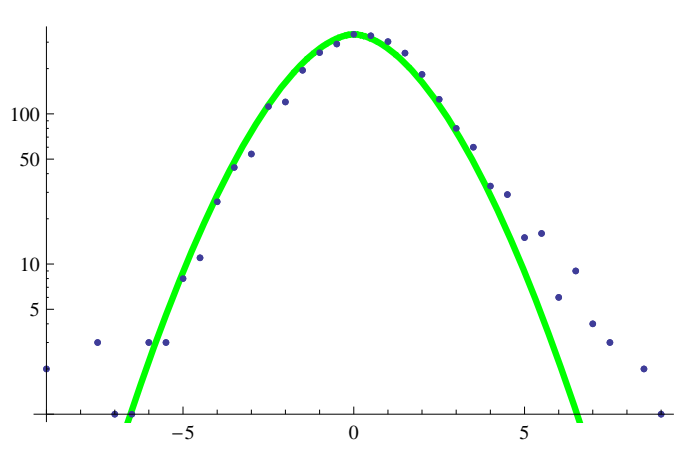

(b) Frequency plot in log scale. The smooth curve is the same Subbotin distribution.

Figure 6: Frequency plots of $\log$ of firm growth $\ln \left(s_{t} / s_{t-1}\right)$ measured by value of sales (bin size of 0.5 ).

botin distribution provided the better fit. Also Fu et al. (2005) conclude that empirical firm growth distributions are 'fatter tailed' than the Laplace and propose a new distribution that has Laplace-like behavior in the center but with substantially heavier tails. The CSA model is therefore consistent with the empirical data on firm growth distributions relative to the uncertainty in the analysis of the empirical data.

\subsection{Rates of Profit}

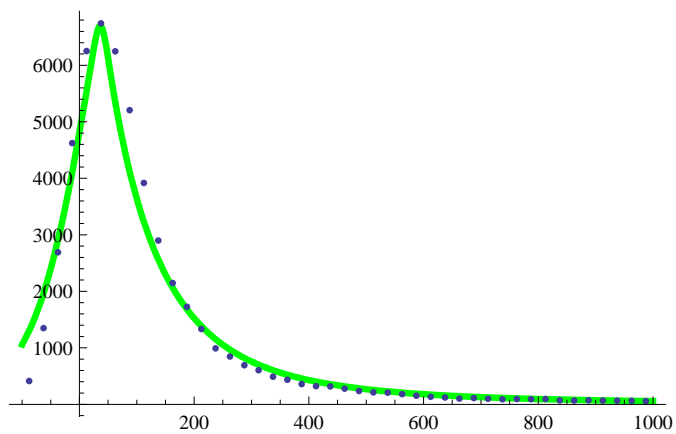

(a) Frequency plot of firm profit rates. The mode of the profit rate is approximately $32.5 \%$.

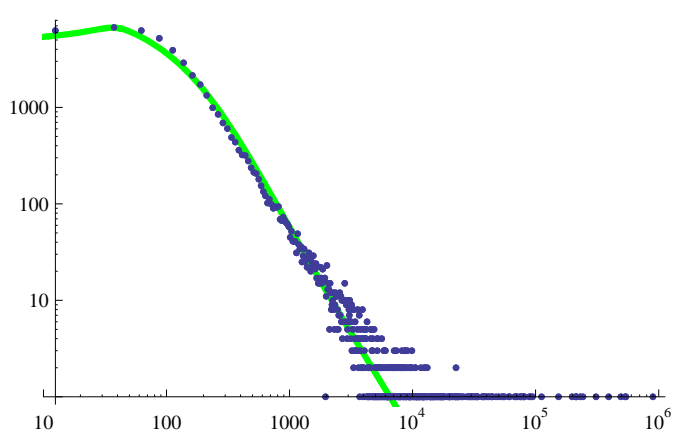

(b) Frequency plot in log-log scale. Note the power-law tail.

Figure 7: Frequency plot of firm profit rates (bin size of 25). The smooth curve is a mixture of normal variates with means and variances distributed according to a power law.

At the end of every year we calculate the profit rate for each firm trading at the close of the year. The profit rate of firm $i$ is $p_{i}=100\left(r_{i} / b_{i}-1\right)$ where $r_{i}$ is total revenue received and $b_{i}$ is total wages paid during the year. Figure 7 plots the result. The distribution is highly right-skewed with a power-law tail. 
I previously deduced a functional form for this profit-rate distribution (Wright, $2004,2005 b)$. Briefly, assume that during a small period of time the revenue generated by each employee of firm $i$ is an independent and identically distributed (iid) random variable. Then by the Central Limit Theorem the firm's revenue, $R_{i}$, is distributed according to a normal distribution. Assume that each individual wage payment to each employee is also iid. Then the firm's wage bill, $W_{i}$, is also normal. The mean and variance of both $R_{i}$ and $W_{i}$ depend on the size of the firm. Larger firms tend to have high revenues and costs that exhibit low variance, whereas smaller firms tend to have low revenues and costs that exhibit high variance. Assume that the size of firms, measured by number of employees, is distributed according to a power-law. So the economy-wide ratio of revenue to costs, $R_{i} / W_{i}$ for all $i$, is a mixture of ratios of normal variates with means and variances distributed according to a power-law.

This argument yields a 6-parameter mixture distribution, $\mathbf{P}: \mu_{1}, \sigma_{1}, \mu_{2}, \sigma_{2}, \alpha, N$, where $\mu_{1}$ is the mean per-capita revenue and $\sigma_{1}^{2}$ the variance, $\mu_{2}$ is the mean wage and $\sigma_{2}^{2}$ the variance, $\alpha$ is the Pareto exponent of the firm size distribution, and $N$ is the number of economic agents. The pdf of mixture $\mathbf{P}$ is $1 / 100 f(1+x / 100)$ where

$$
\begin{aligned}
f(x)= & \int_{2}^{N} \frac{\exp \left[-6\left(\frac{s \mu_{1}^{2}}{\sigma_{1}^{2}}+\frac{(s-1) \mu_{2}^{2}}{\sigma_{2}^{2}}\right)\right]}{2 \pi \Theta^{3 / 2}(x)} \\
& \left(k_{2} \sqrt{\Theta(x)}+\sqrt{6 \pi} \Psi(x) \exp \left[\frac{6 \Psi^{2}(x)}{k_{2}^{2} \Theta(x)}\right]\left(1+\Phi\left(\frac{\sqrt{6} \Psi(x)}{\left.\left.\left.k_{2} \sqrt{\Theta(x)}\right)\right)\right)}\right.\right.\right. \\
& \frac{s^{-(1+\alpha)} \alpha}{1-N^{-\alpha}} d s
\end{aligned}
$$

and

$$
\begin{aligned}
k_{2} & =\sqrt{s \sigma_{1}^{2}} \sqrt{(s-1) \sigma_{2}^{2}} \\
\Theta(x) & =s \sigma_{1}^{2}+(s-1) x^{2} \sigma_{2}^{2} \\
\Psi(x) & =(s-1) s\left(\mu_{2} \sigma_{1}^{2}+x \mu_{1} \sigma_{2}^{2}\right)
\end{aligned}
$$

We can calculate the 6 parameters directly from the simulation. Figure 7 plots $\mathbf{P}$ : $5.0,18,3.0,9.8,0.98,1000$ against the simulation data and demonstrates an excellent fit. Mixture distribution $\mathbf{P}$ therefore includes instances with heavy tails.

The CSA model therefore predicts that empirical profit rates are distributed according to mixture distribution $\mathbf{P}$. This prediction has yet to be tested. The success of the prediction of course depends to what extent the highly simplified assumptions of the model do not abstract from some other essential determinants of the profit rate.

Gibrat (1931) proposed a lognormal distribution for profits. Farjoun and Machover (1989) proposed that the capital-weighted profit-rate is approximated by a gamma distribution by analogy with the distribution of kinetic energy in a gas at equilibrium. Wells (2008) studied UK company accounts data and found that profit rates have power-law tails. The empirical distributions are therefore not consistent with a gamma distribution. Gibrat's hypothesis is 


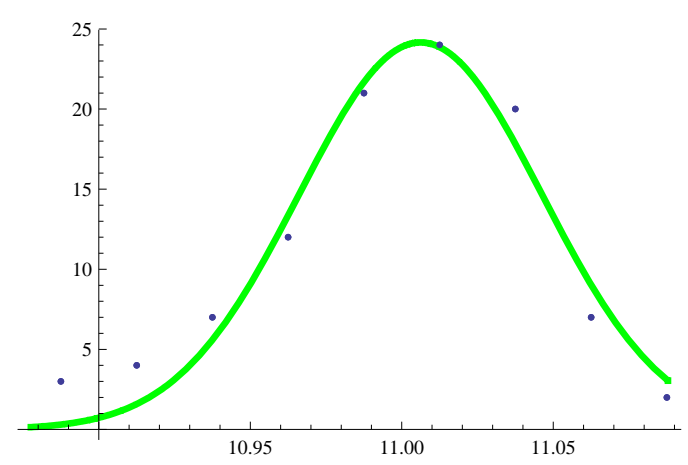

Figure 8: Frequency plot of log of GDP (bin size of 0.025). The smooth curve is the normal distribution $P(x) \propto \frac{1}{\sigma \sqrt{2 \pi}} e^{-(x-\mu)^{2} /\left(2 \sigma^{2}\right)}$ with $\mu=11.0$ and $\sigma=0.04$.

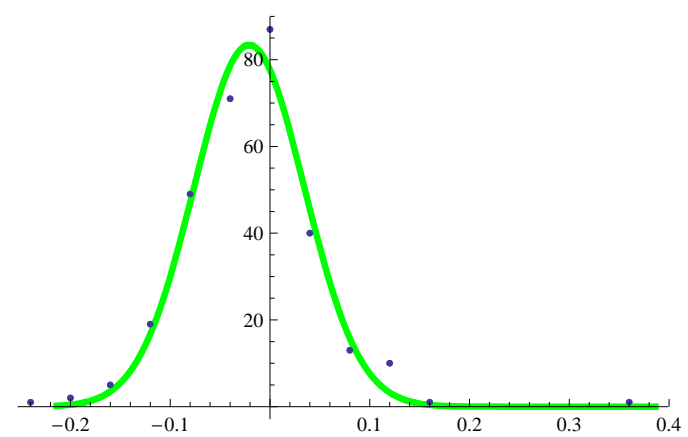

Figure 9: Frequency plot of $\log$ of GDP growth rates $\ln \left(X_{t} / X_{t-1}\right)$ measured over 3 simulations (bin size of 0.05). The smooth curve is the normal distribution $P(x) \propto$ $\frac{1}{\sigma \sqrt{2 \pi}} e^{-(x-\mu)^{2} /\left(2 \sigma^{2}\right)}$ with $\mu=-0.03$ and $\sigma=0.06$.

tentatively verified for some definitions of the profit rate but difficulties remain when fitting the tail of the distribution. The lognormal distribution also fails to fit the tail of the distribution generated by the CSA model.

\subsection{GDP}

Gross Domestic Product (GDP) measures the value of gross production at current prices, including consumption and gross investment. At the close of each year we measure the total firm income, X, received during that year (i.e., all income received during the application of the firm revenue rule). Figure 8 plots the distribution of $\ln (X)$. It is consistent with a normal distribution.

Lee et al. (1998) analyze GDP data of 152 countries during the period 1950-1992 and find that the log of detrended GDP for all countries at all times is consistent with a normal distribution. The CSA model is therefore consistent with the empirical data.

\subsection{GDP Growth}

At the close of year $t$ we calculate the GDP, $X_{t}$. The log growth rate of GDP is then $\ln \left(X_{t} / X_{t-1}\right)$. Figure 9 plots the result, which is consistent with a normal 


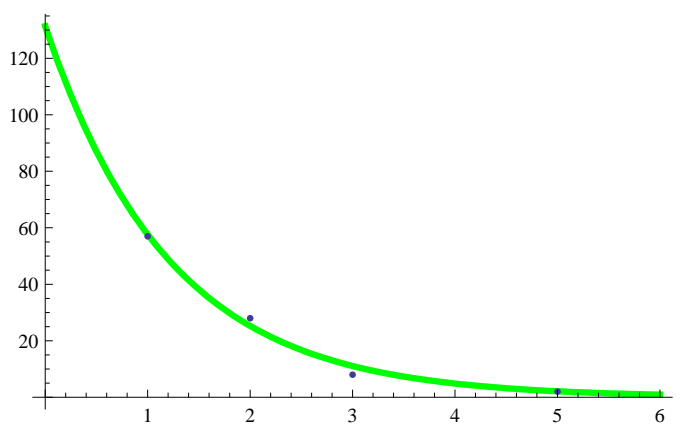

(a) The smooth curve is the exponential distribution $P(x) \propto \lambda e^{-\lambda x}$ with $\lambda=0.83$.

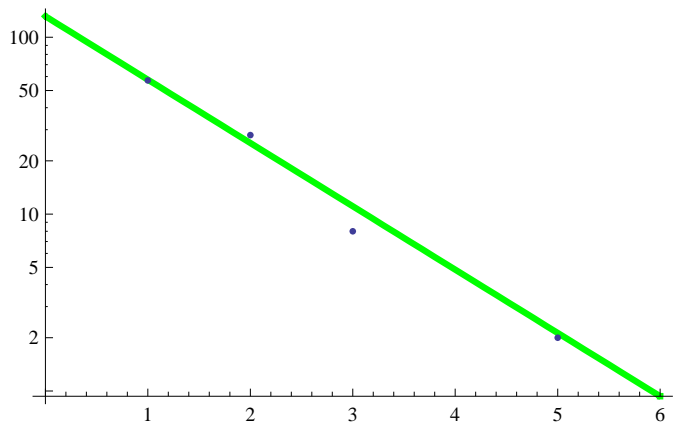

(b) Frequency plot in log scale. The straight line is the same exponential distribution.

Figure 10: Frequency plot of duration of recessions measured in years over 3 simulation runs (bin size of 1 ).

distribution.

Lee et al. (1998) and Canning et al. (1998) analyze the detrended GDP of 152 countries during the period 1950-52 and find that the distribution of GDP log growth rates is consistent with a Laplace distribution. The CSA model therefore fails to replicate the empirical data in this case, which indicates its incompleteness.

\subsection{Duration of Recessions}

A recession begins when $X_{t} / X_{t-1}<1$ and ends when $X_{t+k} / X_{t+k-1} \geq 1$. The duration of the recession is then $k$ years. Figure 10 plots the distribution of the duration of recessions, which follows an exponential law.

Wright (2005a), reinterpreting empirical data presented Ormerod and Mounfield (2001), concludes that for 17 Western economies over the period 1871-1994 the distribution of the duration of recessions follows an exponential law . Recessions tend not to last longer than 6 years, the majority of recessions last 1 year, and for the US the longest recession has been only 4 years (Ormerod, 2002).

Ausloos et al. (2004) subsequently analyzed a more comprehensive set of GDP data and concluded that overall the durations more closely follow a power-law, not an exponential law. In the light of this more extensive data set we must conclude that the CSA model only approximately replicates the empirical distribution.

\subsection{Income Inequality}

At the end of every year we calculate the total income received by each agent during the year. Both wage and firm income are counted as income. So we make no distinction between the income received by a firm and the income received by the capitalist owner. Figure 11 plots the result. The lower regime, corresponding to wage income, is consistent with a lognormal distribution; the higher regime, corresponding to profit income, is consistent with a Pareto distribution. But the lognormal distribution gives a good fit for all income ranges. Deciding between a power-law or lognormal fit for the tail of the data requires statistical, not graphical, analysis. 


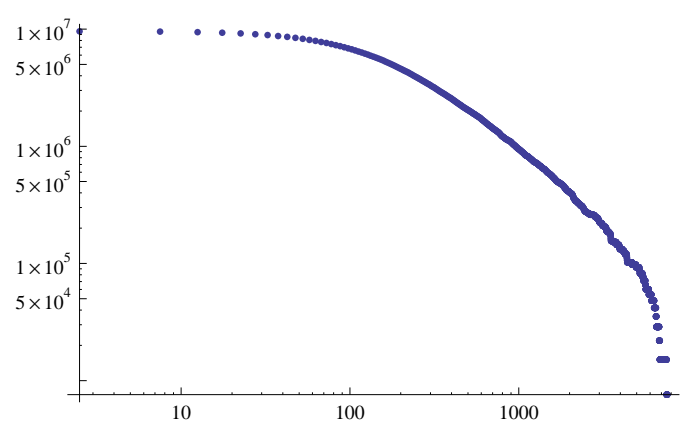

(a) The complete income distribution plotted as complementary cumulative distribution function (ccdf) in log-log scale. A straight line often indicates the presence of a power-law. The transition to a power-law regime occurs in the middle of the ccdf. The long tail is due to the existence of profit income.

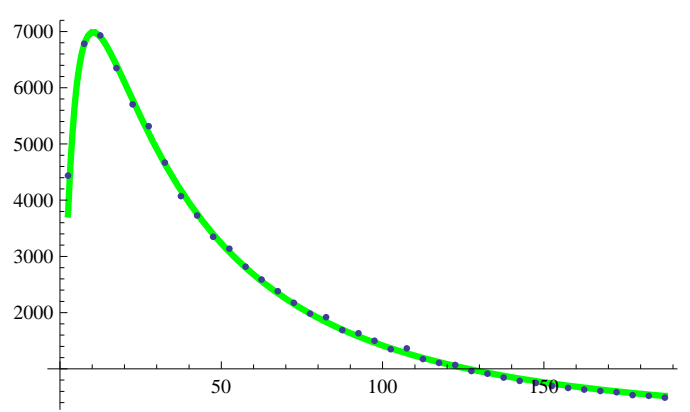

(c) The lower regime of the income distribution. The smooth curve is the lognormal distribution.

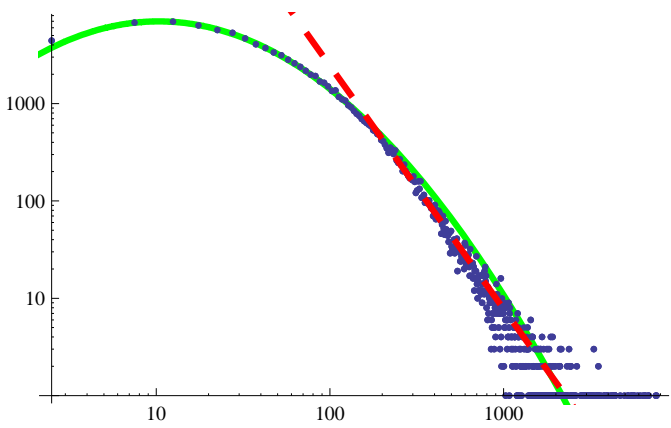

(b) The complete income distribution plotted in log-log scale. The smooth curve is the lognormal distribution $P(x) \propto$ $(1 / \sigma) e^{-\left((\ln x-\mu)^{2} / 2 \sigma^{2}\right)}$. with $\mu=3.9$ and $\sigma=$ 1.3. The dashed straight line is the Pareto distribution $P(x) \propto x^{-(\alpha+1)}$ with $\alpha=1.5$.

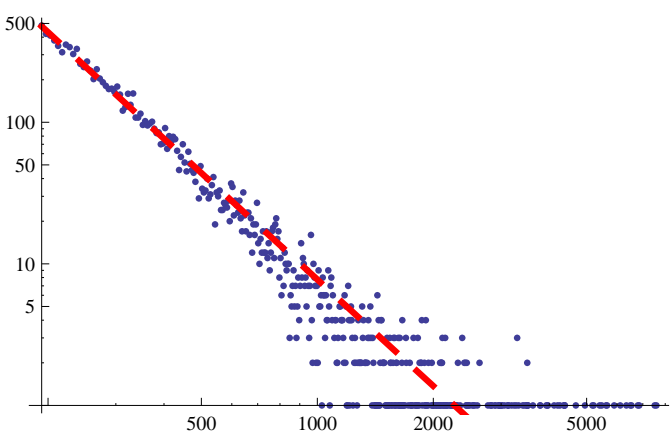

(d) The higher regime of the income distribution plotted in log-log scale. The straight dashed line is the Pareto distribution.

Figure 11: Frequency plots of the distribution of income measured by monies received over the duration of a year (bin size of 5 ).

Empirical studies of the distribution of personal income in capitalist societies are relatively consistent. The higher, profit-income regime is normally fitted to a Pareto (or power) distribution (e.g., Levy and Solomon (1997), Matteo et al. (2003), Dragulescu (2003), Souma (2000), Nirei and Souma (2003a,b, 2007)), whereas the lower, wage-income, regime, which represents the vast majority of the population, is normally fitted to a lognormal distribution (e.g., Souma (2000), Montroll and Shlesinger (1983), Badger (1980)), but recently some researchers (e.g., Nirei and Souma (2003b, 2007), Dragulescu (2003), Dragulescu and Yakovenko (2003)) report that an exponential (Boltzmann-Gibbs) distribution better describes the lower regime. The existence of two income regimes is a direct consequence of the two major sources of income in capitalist societies, that is wages and profits, and the overall income distribution appears to be a mixture of two qualitatively different distributions (Silva and Yakovenko, 2005).

The functional form of the income distribution is stable over many years, al- 
though the parameters seem to fluctuate within narrow bounds. For example, for property-income, the power-law, $P(x) \propto x^{-(\alpha+1)}$, has a value $\alpha=1.3$ for the UK in 1970 (Levy and Solomon), $\alpha=[1.1,1.3]$ for Australia between 1993 and 1997 (Matteo et al., 2003), $\alpha=1.7$ for US in 1998 (Dragulescu, 2003), on average $\alpha=1.0$ for post-war Japan (Nirei and Souma, 2003a), and $\alpha=[0.5,1.5]$ for US and Japan between 1960 and 1999 (Nirei and Souma, 2003b). In sum, the income distribution is asymptotically a power-law with shape parameter $\alpha \approx 1.0$, and this regime normally characterizes the top $1 \%$ to $5 \%$ of incomes. The CSA model is therefore consistent with the empirical data on income distribution.

In the Eeconophysics literature the power-law tail of income distribution is explained as the result of an underlying stochastic multiplicative process, often thought to model the geometric growth of capital invested in financial markets (e.g., Nirei and Souma (2003b,a), Reed (2003, 2001), Levy and Solomon, 1997), Bouchaud and Mezard (2000)). The importance of financial markets in determining capital flows and hence capitalist income is undeniable. But the model developed here shows that a power-law can arise solely from the fact that capitalist owners extract profit from firms (i.e., take the role of residual claimant), even in the absence of financial markets. Capitalist income, in this model, is not derived from investment in portfolios that provide a return, but is composed of the sum of values added via the employment of productive workers. In this sense, capitalist income is 'additive', not 'multiplicative'. But workers are grouped in firms that follow a power-law of size. Hence, the power-law of capitalist income may derive from a power-law in the network structure of the wage-capital relation. But given the simplicity of firm ownership in this model it is too early to conclude anything definite.

\subsection{Wealth Inequality}

At the end of every year we calculate the total money held by each actor. In this model money holdings are a measure of wealth since assets and liabilities are not represented. Figure 12 plots the result. The lower regime of the wealth distribution is characterized by an exponential (or Boltzmann-Gibbs) distribution whereas the higher regime is characterized by a Pareto distribution. The transition between regimes occurs approximately in the middle of the ccdf.

Empirical data on wealth is difficult to find (Yakovenko, 2008). Individuals' access to cash, such as deposits in bank accounts, is not public information. Levy and Solomon (1997) report that in 1996 the top 1\% of individuals in the US owned $40 \%$ of the total wealth. Yakovenko (2008) reports that the net wealth of all UK individuals, estimated by the UK tax agency, has a lower exponential regime and a higher Pareto regime (with exponent $\alpha=1.9$ ). The CSA model is therefore consistent with the small amount of data that is available.

\subsection{Shares in National Income}

GDP is the sum of revenues received by firms during a single year. Firms pay the total wage bill, $W$, from this revenue. Hence the total value of domestic output is divided into a share that workers receive as wages, $X_{w}=\frac{W}{X}$, and the remainder that 


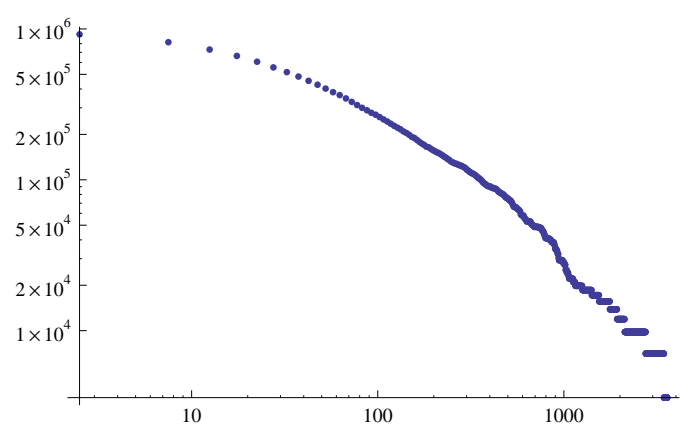

(a) The complete wealth distribution plotted as a ccdf in log-log scale. The transition from the Boltzmann-Gibbs to Pareto regime occurs in the middle of the ccdf.

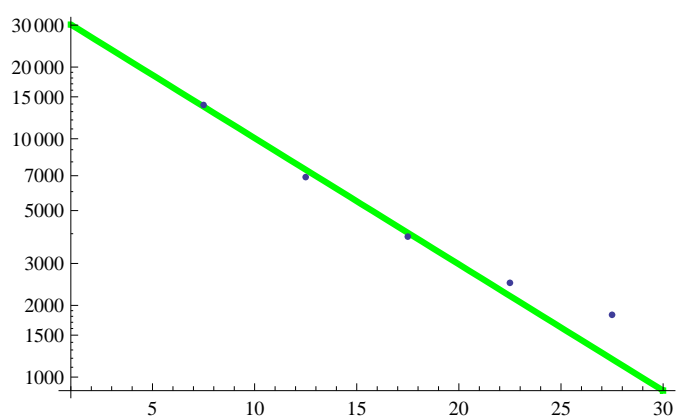

(c) The lower regime of the wealth distribution plotted in log scale. The straight line is the exponential (Boltzmann-Gibbs) distribution.

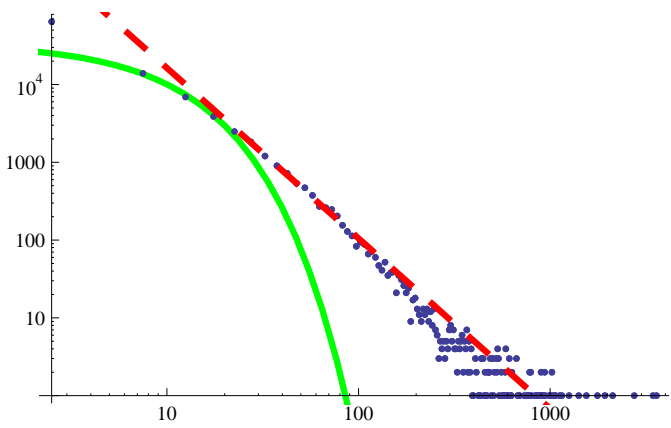

(b) The complete wealth distribution plotted in log-log scale. The smooth curve is the exponential distribution $P(x) \propto e^{-\lambda x}$ with $\lambda=0.12$. The dashed straight line is the Pareto distribution $P(x) \propto x^{-(\alpha+1)}$ with $\alpha=1.2$. Note the long tail due to the existence of wealthy capitalists.

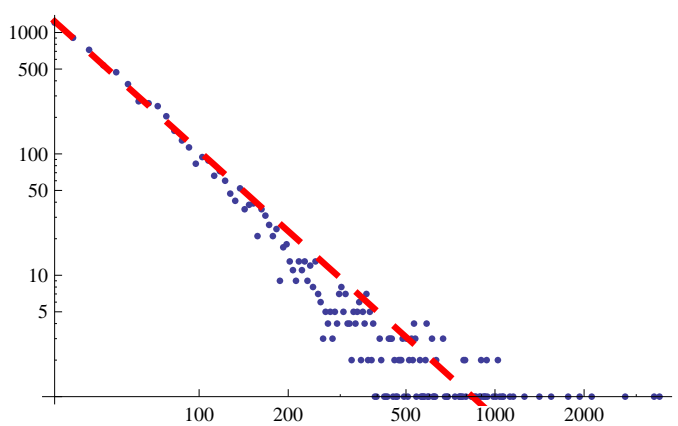

(d) The higher regime of the wealth distribution plotted in log-log scale. The dashed straight line the Pareto distribution.

Figure 12: Frequency plots of the distribution of wealth measured by money holdings at the end of the year (bin size of 5 ).

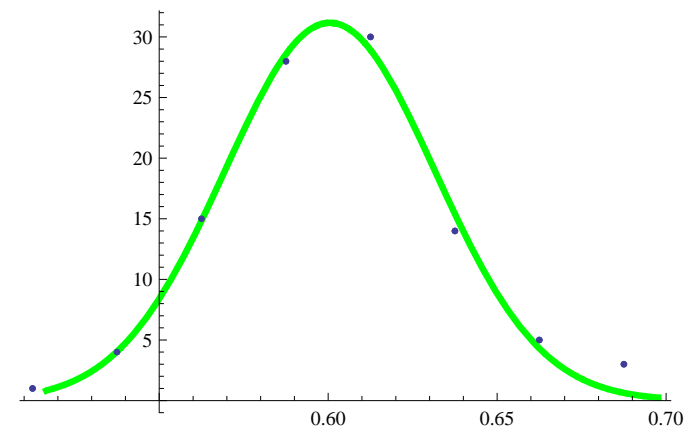

Figure 13: Frequency plot of wage share (bin size of 0.025). The smooth curve is the normal distribution $P(x) \propto \frac{1}{\sigma \sqrt{2 \pi}} e^{-(x-\mu)^{2} /\left(2 \sigma^{2}\right)}$ with $\mu=0.6$ and $\sigma=0.03$.

capitalists receive as profit, $X_{p}=1-X_{w}$. At the end of each year we measure $X_{w}$. Figure 13 plots the result. The wage share is normally distributed about a mean of 


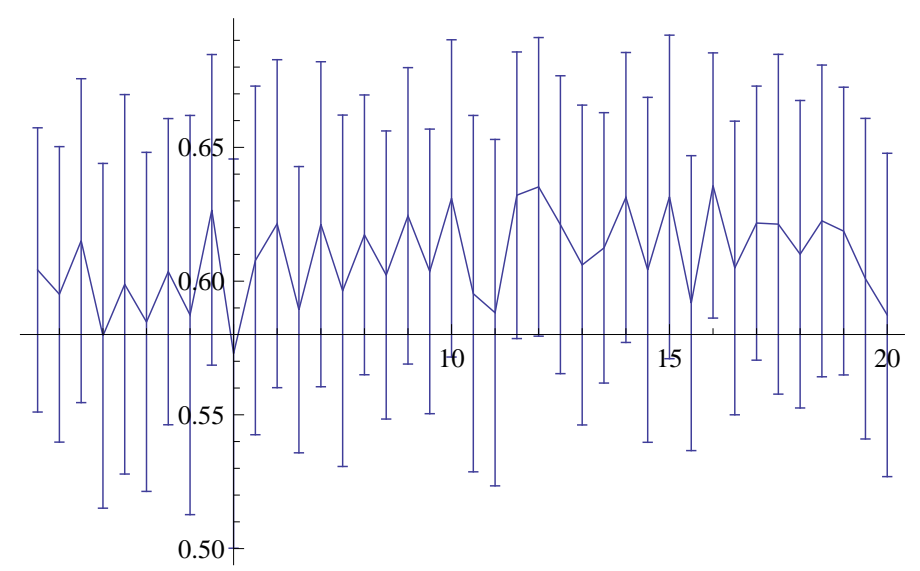

Figure 14: Mean wage share given different seeds for the wage expectation. The wage shares are measured for 100 years after statistical equilibrium is reached. Each sample point is computed from a single run of the model with $N=100, M=1000$ and an initial wage expectation ranging from 0.5 to 20 in steps of 0.5 . The error bars represent standard deviation. Mean wage shares are clustered around 0.61 with a std. dev. of 0.02 .

0.6 (i.e., on average $60 \%$ of GDP is allocated as wages).

National income accounts allow wage and profit shares to be calculated, which reveal some characteristic features. Shares in national income have remained fairly stable during the twentieth century, despite undergoing yearly fluctuations. For example, for the US, UK and Japan, spanning a period of over 100 years, the wage share is between 0.6 to 0.75 of GDP, although it occasionally can be as low as 0.5 (Foley and Michl, 1999); other authors place the wage share nearer to $1 / 2$, for example on average 0.54 between 1929 and 1941 for the USA (Kalecki, 1954) and similar in chapters 3 and 8 of Farjoun and Machover (1989). The constancy of income shares of capital and labor is sometimes referred to as 'Bowley's Law' after the statistician who first noted the regularity (Fischer (1999), p.294).

Ignoring differences of definition, and for the purposes of a rough and ready comparison, the CSA model generates a wage share that is consistent with the empirical data.

To what extent is this result sensitive to the seed values for the wage expectation? Figure 14 plots the result of varying the initial wage expectation on the wage share in statistical equilibrium. Although not a proof the results indicate that the initial seed values have no effect. 6 Wage negotiations are private and uncoordinated yet constrained by the total money stock and the demand for labor. So subjective wage expectations quickly get calibrated by the 'sum total of the actions of all the rest'.

In the CSA model no distinction is made between employer accounts and firm accounts. So an employer's contribution to effective demand is interpreted as a mixture of personal consumption and capital investment in the firm. The 'effective demand rule' states that firms allocate a proportion of their income to non-wage

\footnotetext{
${ }^{6}$ The results also indicate, as expected, that the population size, $N$, and money stock, $M$, do not affect the equilibrium wage share. An economy with $N=1000$ and $M=10000$ generates the same wage share as an economy with $N=100$ and $M=1000$.
} 
costs according to a uniform distribution. The proportion is therefore on average one half. This happens to generate a reasonable wage share. So although the CSA model replicates something like Bowley's law it does not explain it. To do so requires further extensions to the model, in particular a theory of capital investment.

\section{Conclusion}

A large market economy has a huge number of degrees of freedom with weak microlevel coordination. In such circumstances the 'particle' nature of individuals more strongly determines macro-level outcomes compared to their 'mechanical' nature. A broad range of macroeconomic phenomena can therefore be explained without recourse to detailed assumptions about individual rationality.

The 'closed social architecture' model is a particular example of this methodological approach. It replicates many of the reported macroeconomic distributions of capitalist economies, such as (i) the Laplace distribution of firm growth, (ii) the power-law distribution of firm sizes, (iii) the lognormal distribution of firm demises, (iv) the exponential distribution of firm lifespans, (v) the normal distribution of the log of detrended GDP, (vi) the exponential distribution of the duration of recessions, (vii) the lognormal-Pareto distribution of income, (viii) the exponential-Pareto distribution of wealth, and (ix) stable but fluctuating shares in national income. The model also predicts a functional form for the empirical distribution of the industrial profit rate.

The results are strong evidence in favor of the proposition that implicit, rather than explicit, microfoundations better capture the essential relationships between the micro and macro levels of the economy. The exploration of stochastic-based macroeconomic models featuring implicit microfoundations therefore presents us with an opportunity to develop more parsimonious theories with greater explanatory power.

\section{References}

Amaral, L. A. N., S. V. Buldyrev, S. Havlin, H. Leschhorn, F. Maass and M. A. Salinger (1997). Scaling behavior in economics: I. Empirical results for company growth. Journal de Physique I France 7: 621-633.

Amaral, L. A. N., P. Gopikrishnan, V. Plerou and H. E. Stanley (2001). A model for the growth dynamics of economic organizations. Physica A 299: 127-136.

Aoki, M. (1996). New approaches to macroeconomic modeling: Evolutionary stochastic dynamics, multiple equilibria, and externalities as field effects. Cambridge: Cambridge University Press.

Aoki, M. (2002). Modeling aggregate behavior and fluctuations in economics. Cambridge: Cambridge University Press. 
Aoki, M. and H. Yoshikawa (2007). Non-self-averaging in macroeconomic models: A criticism of modern micro-founded macroeconomics. Economics Discussion Papers (2007-49). URL http://www . economics-ejournal org/economics/discussionpapers/2007-49.

Ausloos, M., J. Miskiewicz and M. Sanglier (2004). The duration of recession and prosperity: Does their distribution follow a power or an exponential law? Physica A pp. 548-558.

Axtell, R. L. (2001). Zipf distribution of U.S. firm sizes. Science 293: 1818-1820.

Badger, W. W. (1980). An entropy-utility model for the size distribution of income. In B. J. West (ed.), Mathematical models as a tool for social science, pp. 87-120. New York: Gordon and Breach.

Bottazzi, G. and A. Secchi (2003). Explaining the distribution of firms growth rates. Working paper S. Anna School for Advanced Studies, Pisa, Italy.

Bouchaud, J.-P. and M. Mezard (2000). Wealth condenstation in a simple model of economy. Physica A 282: 536.

Bureau of Labor Statistics (2008). News. USDL 08-1049. URL http://www.bls.gov/news.release/pdf/empsit.pdf.

Canning, D., L. A. N. Amaral, Y. Lee, M. Meyer and H. E. Stanley (1998). Scaling the volatility of gdp growth rates. Economics Letters 60: 335-341.

Cook, W. and P. Ormerod (2003). Power law distribution of the frequency of demises of us firms. Physica A 324: 207-212.

Cottrell, A. F., P. Cockshott, G. J. Michaelson, I. P. Wright and V. M. Yakovenko (2009). Classical Econophysics. Routledge Advances in Experimental and Computable Economics, London: Routledge.

Debreu, G. (1959). Theory of value - An axiomatic analysis of economic equilibrium. New Haven and London: Yale University Press.

Dragulescu, A. and V. M. Yakovenko (2000). Statistical mechanics of money. The European Physical Journal B 17: 723-729.

Dragulescu, A. and V. M. Yakovenko (2003). Statistical mechanics of money, income and wealth: a short survey. In Modeling of Complex Systems: Seventh Granada Lectures: AIP Conference Proceedings, pp. 180-183. New York.

Dragulescu, A. A. (2003). Applications of Physics to economics and finance: Money, income, wealth, and the stock market. Ph.D. thesis, Department of Physics, University of Maryland, USA. URL http://arXiv.org/abs/cond-mat/0307341.

Farjoun, E. and M. Machover (1989). Laws of Chaos, a Probabilistic Approach to Political Economy. London: Verso. Available online at www.probabilisticpoliticaleconomy.net. 
Farmer, J. D., P. Patelli and Z. Ilija I (2005). The predictive power of zero intelligence in financial markets. Proceedings of the National Academy of Sciences of the United States of America 102 (6): 2254-2259.

Fischer, D. H. (1999). The Great Wave: Price Revolutions and the Rhythm of History. Oxford University Press.

Foley, D. K. (1994). A statistical equilibrium theory of markets. Journal of Economic Theory 62: 321-345.

Foley, D. K. and T. R. Michl (1999). Growth and Distribution. Cambridge, Massachusetts: Harvard University Press.

Fu, D., F. Pammolli, S. V. Buldyrev, M. Riccaboni, K. Matia and K. Yamasaki (2005). The growth rate of business firms: Theoretical framework and empirical evidence. Proceedings of the National Academy of Science 102 (52): 18801-18806.

Fujiwara, Y. (2003). Zipf law in firms bankruptcy. URL arXiv: cond-mat/0310062v1.

Fujiwara, Y. (2004). Zipf law in firms bankruptcy, Physica A 337 (1-2): 219-230.

Gaffeo, E., M. Catalano, F. Clementi, D. D. Gatti, M. Gallegati and A. Russo (2007). Reflections on modern macroeconomics: Can we travel along a safer road? Physica A 382: 89-97.

Gaffeo, E., M. Gallegati and A. Palestrini (2003). On the size distribution of firms: Additional evidence from the G7 countries. Physica A 324: 117-123.

Gatti, D. D., C. D. Guilmi, E. Gaffeo and M. Gallegati (2004). Bankruptcy as an exit mechanism for systems with a variable number of components. Physica $A$ 344: 8-13.

Gibrat, R. (1931). Les inégalités économiques. Paris: Sirey.

Gode, D. and S. Sunder (1993). Allocative efficiency of markets with zero intelligence traders: Markets as a partial substitute for individual rationality. Journal of Political Economy 101: 119-137.

Hart, P. E. and S. J. Prais (1956). The analysis of business concentration: A statistical approach. Journal of the Royal Statistical Society 119: 150-191.

Kalecki, M. (1954). Theory of Economic Dynamics. New York: Rinehart and Company Inc.

Khinchin, A. I. (1949). Mathematical foundations of statistical mechanics. Dover Publications.

Kirman, A. (1992). Whom or what does the representative agent represent? Journal of Economic Perspectives 6: 117-136. 
Kydland, F. E. and E. C. Prescott (1982). Time to build and aggregate fluctuations. Econometrica 50 (6): 1345-1370.

Lee, Y., L. A. N. Amaral, D. Canning, M. Meyer and H. E. Stanley (1998). Universal features in the growth dynamics of complex organizations. Physical Review Letters 81 (15): 3275-3278.

Levy, M. and S. Solomon (1996). Of wealth power and law: The origin of scaling in economics. Submitted for publication. URL http://shum.cc.huji.ac.il/ sorin/ps/nature.ps

Levy, M. and S. Solomon (1997). New evidence for the power-law distribution of wealth, Physica A 242: 90-94.

Lin, L. (2008). Some extensions to the social architecture model. In J. Wells, E. Sheppard and I. Wright (eds.) Proceedings of Probabilistic Political Economy: Laws of Chaos in the 21st Century. Kingston University, UK.

Marx, K. (1954). Capital, vol. 1. Moscow: Progress Publishers. Original English edition published in 1887.

Matteo, T. D., T. Aste and S. T. Hyde (2003). Exchanges in complex networks: Income and wealth distributions. To appear in Nuova Cimento. URL http://arXiv.org/abs/cond-mat/0310544arXiv:cond-mat/0310062v.

Mirowski, P. (1989). More Heat than Light: Economics as social physics, physics as nature's economics. Cambridge: Cambridge University Press.

Montroll, E. W. and M. F. Shlesinger (1983). Maximum entropy formalism, fractals, scaling phenomena, and 1/f noise: a tale of tails. Journal of Statistical Physics 32: $209-230$.

Nirei, M. and W. Souma (2003a). Income distribution and stochastic multiplicative process with reset events. URL http://www.santanfe.edu/ makato/papers/income.pdf.

Nirei, M. and W. Souma (2003b). Income distribution dynamics: a classical perspective. URL http://www. santafe.edu/ makato/papers/income.pdf.

Nirei, M. and W. Souma (2007). A two factor model of income distribution dynamics. Review of Income and Wealth 53 (3): 440-459.

Ormerod, P. (2002). The US business cycle: power law scaling for interacting units with complex internal structure. Physica A 314: 774-785.

Ormerod, P. and C. Mounfield (2001). Power law distribution of the duration and magnitude of recessions in capitalist economies: Breakdown of scaling. Physica $A$ 293: 573-582.

Reed, W. J. (2001). The Pareto, Zipf and other power laws. Economics Letters 74: 15-19. 
Reed, W. J. (2003). The Pareto law of incomes - An explanation and an extension. Physica A 319: 469-486.

Rivzi, S. A. T. (1994). The microfoundations project in general equilibrium theory. Cambridge Journal of Economics 18: 357-377.

Silva, A. C. and V. M. Yakovenko (2005). Temporal evolution of the 'thermal' and 'superthermal' income classes in the USA during 1983-2001. Europhysics Letters 69 (2): 304-310.

Simon, H. A. and C. P. Bonini (1958). The size distribution of business firms. American Economic Review 48 (4): 607-617.

Souma, W. (2000). Physics of personal income. In H. Takayasu (ed.), Empirical science of financial fluctuations: The advent of econophysics. Tokyo: Nihon Keizai Shimbun, Inc. URL http://arxiv.org/abs/cond-mat/0202388.

Stanley, M. H. R., N. L. A. Amaral, S. V. Buldyrev, S. Havlin, H. Leschhorn, P. Maass, M. A. Salinger and H. E. Stanley (1996). Scaling behavior in the growth of companies. Nature 379: 804-806.

Steindl, J. (1965). Random processes and the growth of firms. London: Charles Griffin and Co. Ltd.

Teitelbaum, D. and R. Axtell (2005). Firm size dynamics and industries: Stochastic growth processes, large fluctuations and the population of firms as a complex system. Small Business Administration Research Summary No. 247. Published under SBA contract SBAHQ-03-Q-0015.

Wells, J. (2008). The rate of profit as a random variable. Ph.D. thesis, Department of Economics, The Open University, UK. URL http://staffnet.kingston.ac.uk/ ku32530/phdindex.html.

Wright, I. (2004). A conjecture on the distribution of firm profit. Economía: Teoría y Práctica 20.

Wright, I. (2005a). The duration of recessions follows an exponential not a power law. Physica A 345: 608-610.

Wright, I. (2005b). The social architecture of capitalism. Physica A 346: 589-622.

Wright, I. (2008). The emergence of the law of value in a dynamic simple commodity economy. Review of Political Economy 20 (3): 367-391.

Yakovenko, V. M. (2008). Econophysics, statistical mechanics approach to. In B. Meyers (ed.), Encyclopedia of Complexity and System Science. Springer. 


\section{Appendix: Mathematica code}

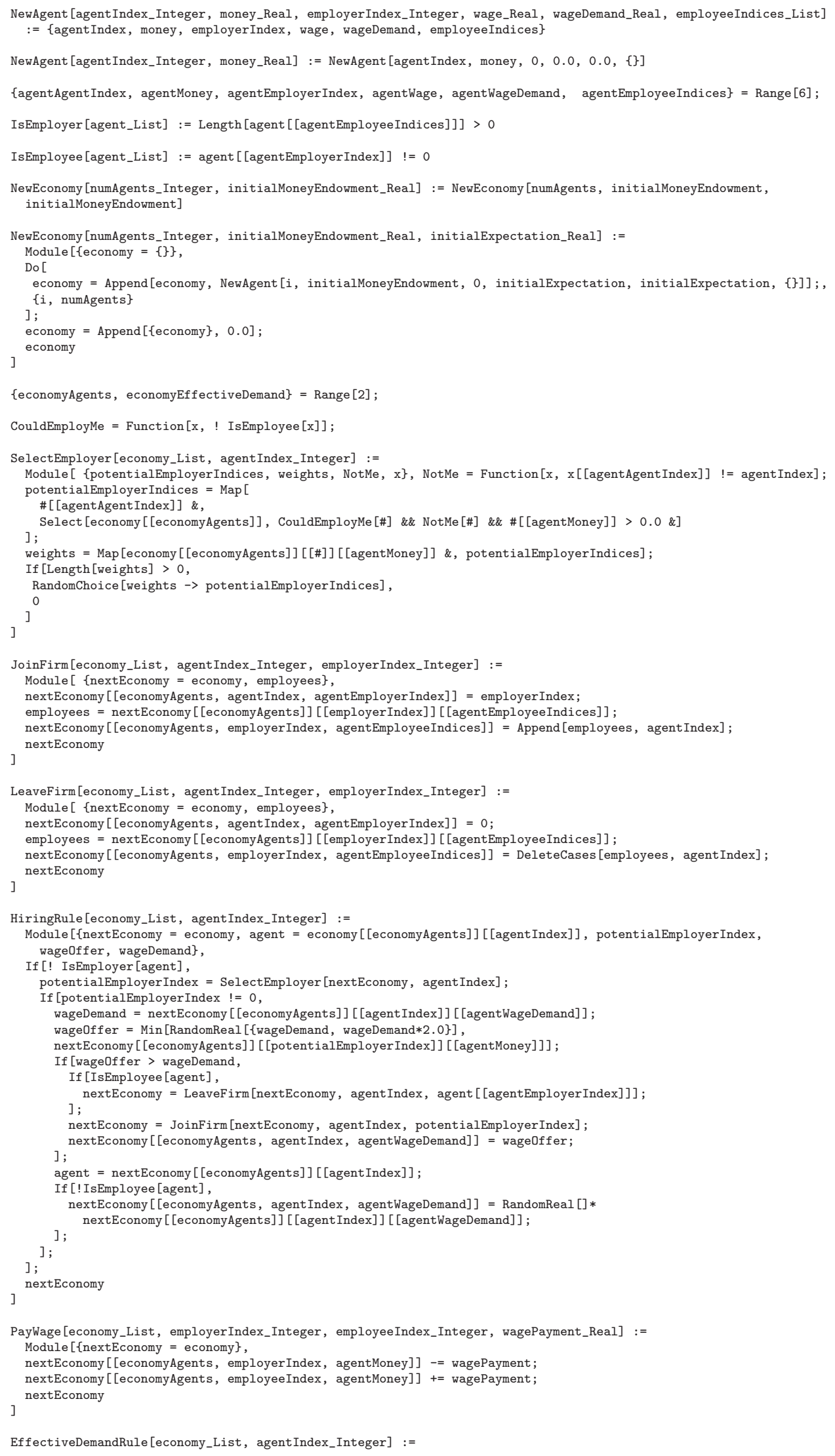




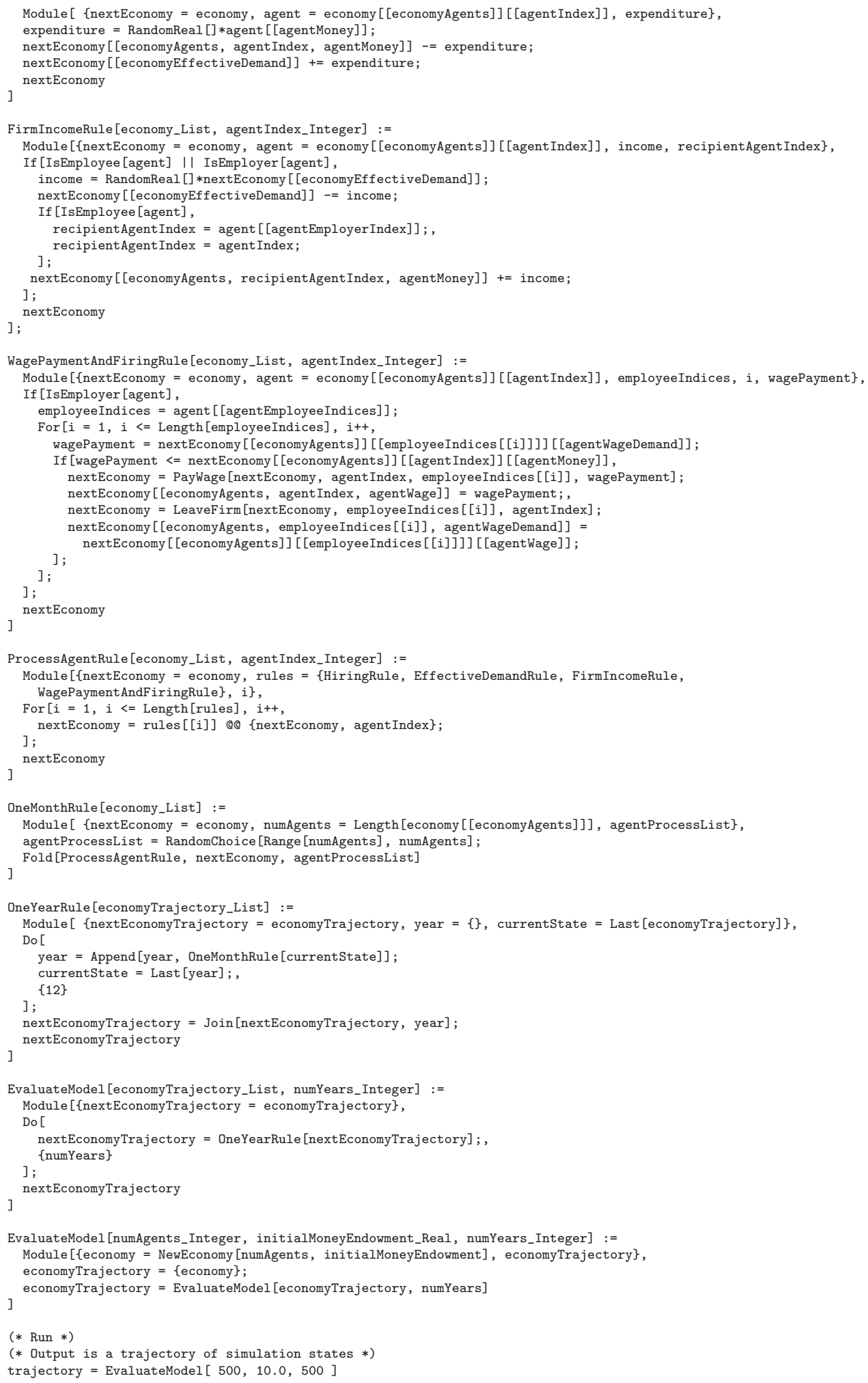




\section{conomics}

The Open-Access, Open-Assessment E-Journal

\section{Please note:}

You are most sincerely encouraged to participate in the open assessment of this article. You can do so by either rating the article on a scale from 1 (bad) to 5 (excellent) or by posting your comments.

Please go to:

www.economics-ejournal.org/economics/journalarticles/2009-19

The Editor 